\title{
ARTE CERÂMICA NA AMAZÔNIA: UM RELATO SOBRE $O$ SABER FAZER DAS LOUCEIRAS DO MARUANUM, NO AMAPÁ
}

\author{
Elloane Carinie Gomes Silva (D)
}

\author{
Doutoranda em Desenvolvimento Sustentável do Trópico Úmido
}




\section{RESUMO}

Esta pesquisa parte de um relato etnográfico acerca dos saberes resguardados pelas louceiras do Maruanum, no estado do Amapá, na Amazônia brasileira. É proposta uma análise centrada na leitura de elementos que compõem a linguagem concreta e intersubjetiva dos objetos confeccionados pelas ceramistas com a intenção de desvelar características socioculturais e identitárias em dias atuais. Partindo da abordagem qualitativa, com objetivo exploratório-descritivo e interpretativo, foram conduzidas as pesquisas teórica, documental e em campo. Este texto introduz uma experiência de compartilhamento contínuo que busca novas maneiras de olhar sujeitos e objetos. Na dada realidade social, as questões centrais se voltam para a importância da valorização do conhecimento tradicional das mulheres ceramistas e a preservação e conservação da arte do quilombo, que fornece elementos inspiradores para a criatividade humana, relações sociais e harmonia com a natureza.

Palavras-chave: Louceiras do Maruanum; Arte cerâmica; Amazônia.

\section{CERAMIC ART IN THE AMAZON: AN ACCOUNT OF THE KNOW-HOW OF THE MARUANUM CHINAWARE, IN AMAPÁ}

\section{ABSTRACT}

This research is based on an ethnographic report concerning the knowledge protected by the tableware makers (craftswomen) of the Maruanum, in the state of Amapá, Brazilian Amazon. It is proposed an analysis centered on the reading of elements that compose the concrete and intersubjective language of the objects made by the ceramists with the intention of revealing their current sociocultural and identity characteristics. Based on a qualitative approach, with an exploratory-descriptive and interpretive objective, theoretical, documental and field researches are conducted. This text introduces a continuous sharing experience that seeks new ways of looking at subjects and objects. In a given social reality, the central issues turn to the importance of valuing the craftswomen traditional knowledge and the preservation and conservation of quilombo art, which provides inspiring elements for human creativity, social relations and harmony with nature.

Keywords: Maruanum tableware makers; Earthenware; Amazon region.

\section{ARTE CERÁMICO EN LA AMAZONÍA: UN RELA- TO DEL SABER HACER DE LA ALFARERÍA EN EL MARUANUM, EN AMAPÁ}

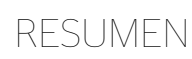

Esta investigación consiste en un relato etnográfico sobre la creación cultural de mujeres alfareras de Maruanum, en el estado de Amapá, región de la Amazonía brasileña. Se propone um análisis centrado en la lectura de elementos que componen el lenguaje concreto e intersubjetivo de los objetos realizados por ceramistas con la intención de desvelar sus características socioculturales e identitarias en la actualidad. Con base en el enfoque cualitativo, con un objetivo exploratorio-descriptivo e interpretativo, se realizan investigaciones teóricas, documentales y de campo. Este texto introduce una experiencia de intercambio continuo que busca nuevas formas de mirar sujetos y objetos. En una determinada realidad social, los temas centrales giran en torno a la importancia de valorar los conocimientos tradicionales de las alfareras y la preservación y conservación del arte quilombola, que aporta elementos inspiradores para la creatividad humana, las relaciones sociales y la armonía con la naturaleza.

Palabras clave: Louceras do Maruanum; Arte cerámico; Amazonía. 


\section{INTRODUÇÃO}

Passados trinta anos desde o estudo limiar de Alicia Coirolo (1991) intitulado "Atividades e tradições dos grupos ceramistas do Maruanum (AP)" - publicado na série Antropologia do Boletim do Museu Paraense Emílio Goeldi -, é apresentado neste trabalho um relato etnográfico acerca das obras culturais confeccionadas pelas louceiras da comunidade quilombola do Maruanum, no Amapá, com a intenção de desvelar características socioculturais e marcadores identitários em dias atuais. A análise esteve centrada na leitura de elementos que compõem a linguagem concreta e intersubjetiva dos objetos associada aos diálogos provenientes de experiências compartilhadas com as mulheres ceramistas.

Nesse processo contínuo de objetivação e conceitualização, o que se busca aqui não é uma síntese de forças, mas interlocuções entre as práticas de conhecimento que permitam interpretações próprias e significativas da arte produzida pelas louceiras do Maruanum. Este texto é o início de um novo projeto de pesquisa desenvolvido junto ao Núcleo de Altos Estudos Amazônicos (NAEA) simultaneamente a uma nova experiência de compartilhamento junto à tia Marciana, Mundoca, Deuza, Zezé e a todas as mulheres do Maruanum que resguardam saberes nos quais é refletido um complexo universo socioecológico e cultural.

Nesse contexto, concordo com Krenak (2019) ao tratar da importância de viver a experiência de nossa própria circulação no mundo não como metáfora, mas como fricção; assim, uma das ideias para adiar o fim do mundo é contar mais histórias diante das ausências criadas pelo nosso tempo. Minha visão das ciências coaduna-se com aquela de Stengers (2002), para quem o pensamento científico não é acrítico, mas também não é uma simples prática do conhecimento humano redutível às explicações e teses. O laço afetivo com o conhecimento científico - desde minha infância - representa uma primeira ruptura paradigmática de minha construção enquanto pesquisadora, pois o encantamento pela ciência é raro em uma sociedade que a instrumentaliza pela técnica e a controla segundo a lógica mercantil.

Krenak (2019: 44) diz que há muito tempo não existe alguém que pense com a liberdade do cientista - "acabaram os cientistas". Isso faz parte do desastre do nosso tempo, do abismo em que nos encontramos onde a esperança é inventar e construir diversos paraquedas coloridos, originados de um lugar de conexão com o mundo que partilhamos (Krenak 2019). Encontrei um desses lugares! Quem me mostrou foi tia Marciana, às margens do rio Maruanum. Nosso diálogo foi assim: 
“- Dona Marciana, como se faz a louça de barro do Maruanum?

- Ah minha filha...Tem toda uma ciência!"

(Trecho retirado do diário de campo da autora 2019)

Enquanto eu acompanhava tia Marciana na feitura das louças, ela cantava os versos do Marabaixo $^{1}$ e conversava sobre a sua visão de mundo. Entendi que o conhecimento que nutria as suas práticas artístico-culturais trazia uma compreensão muito profunda acerca da natureza e de sua própria existência. Isso me fez enxergar a liberdade do pensamento e a diversidade do saber no que tange, em uma perspectiva foucaultiana, a subjetivação do sujeito. O saber das louceiras do Maruanum é uma prática socioartística e cultural de tradição secular, conectada às múltiplas identidades das mulheres quilombolas, evidenciando um complexo sistema conceitual e representacional por meio da arte, corpo, técnica, simbolismos e encantaria ${ }^{2}$.

Nesse caminho, este estudo parte de uma abordagem qualitativa, com objetivo exploratóriodescritivo e interpretativo, para a condução das pesquisas bibliográficas e documentais que versam sobre aspectos históricos, sociais e estéticos ${ }^{3} \mathrm{da}$ formação social na Amazônia. Ainda usando como base o estudo de Coirolo (1991) foram associados para as discussões os trabalhos de Costa, Lima e Custódio (2016), Ferreira (2016), Jacques (2015), Silvani (2012), dentre outros, que auxiliaram na construção das interpretações do conteúdo artístico e sociocultural presente nas louças de barro do Maruanum.

Os primeiros estudos realizados em campo adotaram a observação participante (Flick 2004) e ocorreram nos meses de novembro e dezembro de 2018 e abril de 2019 na comunidade de Santa Luzia - distante $70 \mathrm{~km}$ da cidade de Macapá, capital do estado do Amapá. Foram combinadas distintas técnicas, a saber: entrevista em profundidade com grupo focal ${ }^{4}$ e o diário de campo, onde foram registradas as impressões captadas no contato com o ambiente e com as pessoas. Assim, foi adotada a compreensão de que a prática se encontra na relação social de investigação como preconiza Bourdieu (2011). Essa mesma relação está imbricada no olhar dialético, o olhar em movimento que busca captar o objeto em sua perspectiva histórica e de mudanças e contradições (Cavalcanti 2014).

1 Manifestação cultural de origem africana praticada no Amapá desde o século XVII com a vinda dos negros para a região. Em 2018 foi salvaguardada como patrimônio cultural do Brasil pelo Instituto do Patrimônio Histórico e Artístico Nacional (Iphan 2018).

2 Linguagem fecundante da cultura amazônica que mescla elementos reais e não reais de suas cosmologias, representa uma das mais raras permanências de atmosfera poética-estetizante nas formas de vivências (Loureiro 2016).

3 Aspecto considerado fecundante na cultura amazônica (Loureiro 2018).

4 Registros assegurados pelo Termo de Consentimento Livre e Esclarecido associado à Autorização de imagem e vídeo. 


\section{MARU + ANUM: ORIGENS E MITOS}

Assim como em sua história pré-colombiana, o Amapá ofertou encontros entre inúmeras etnias vindas da África e com os próprios indígenas da região (Ferreira 2016), assim, a população presente na comunidade do Maruanum está integrada pelas culturas indígena e africana, vívidas em suas tradições e manifestações culturais e religiosas (Santos 2016). No que tange às dinâmicas de aquilombamento ${ }^{5}$ na construção histórico-geográfica do Amapá, a formação dos quilombos na região foi marcada pela presença de africanos e indígenas, fugitivos de Macapá, Mazagão, Guiana Francesa e do baixo Amazonas, no Pará (Gomes 1999, Silva 2015). Ao dialogar com historiografias dos contatos indígenas e africanos na Amazônia, Pacheco (2012) infere que os quilombos e mocambos foram quase sempre afro-indígenas, isso não significa negar as raízes identitárias tradicionais com as quais os povos falam por si, mas evidencia entre suas múltiplas identidades a de afro-indígena, pois se formaram culturalmente nesses códigos que sustentam o tecido histórico-social da região.

Com base no estudo de Coirolo (1991) e no

de Silvani (2012), bem como no diário de campo desta pesquisa, foram identificadas três versões da origem do nome Maruanum, a primeira delas trata de uma lenda ${ }^{6}$ indígena na qual o guerreiro Maru casou-se com Anum e "pediu a ajuda de Tupã para conduzi-los a uma localidade bonita e fértil onde pudessem viver" (Silvani 2012: 38), desse amor nasceu o rio Maruanum. A segunda versão encontrada nos estudos de Coirolo (1991:74) trata de uma "versão adquirida", contada aqui por uma moradora da comunidade:

\begin{abstract}
"Vinha uma canoa passando no rio e chegando bem na boca desse igarapé tinha um bocado de anuns e eles, os da canoa, perguntaram a uma pessoa como se chamava esse igarapé e a pessoa do lugar respondeu-lhes que era o "Mar de Anum", daí virou Maruanum”.
\end{abstract}

Essa narrativa foi reafirmada por dona Marciana $^{7}$ durante uma conversa registrada no diário de campo. Uma terceira versão, fornecida por Josilana Santos ${ }^{8}$, conta que:
“Os marus eram uma tribo de índios
que viviam na região e os anum eram
como eram chamados pelos padres
lusitanos, os negros que foram morar
naquela região. Então, quando eles
diziam: "Que região? Daonde é esse
povo?". [...] "É lá onde mora os marus
e os anuns". Aí virou Maruanum!"

\footnotetext{
5 Se refere à formação de quilombos (Silva 2015).
}

6 Segundo Cascudo (2001: 511) a lenda pode ser descrita como "um episódio heróico ou sentimental com o elemento maravilhoso ou sobre-humano, transmitido e conservado na tradição oral popular, localizável no espaço e no tempo". Ela conserva quatro características do conto popular: antiguidade, persistência, anonimato e oralidade. Os processos de transmissão, circulação e convergência se assemelham com aqueles que presidem a literatura oral.

7 Moradora de Santa Luzia, ceramista e líder do coletivo formado pelas louceiras do Maruanum.

8 Filha da comunidade, professora e articuladora política. Atualmente ocupa o cargo de Secretária Adjunta do Instituto Municipal de Políticas de Promoção de Igualdade Racial (IMPROIR). 
A cosmologia desse pensamento é fértil assim como os modos de vida compartilhados entre as vilas banhadas pelo rio Maruanum, afluente do rio Matapi, ambos sujeitos às marés do rio Amazonas (Coirolo 1991). A figura 1 apresenta a localização da região.

As vilas que formam o Maruanum se organizam em núcleos familiares, dentre elas:
Santa Luzia, Vila do Carmo, Torrão, Simião, Conceição, Fátima, São Raimundo, Santa Maria, São Pedro, São José e São Tomé. Vale ressaltar que elas também incorporam ramais de acesso com moradores, o que por vezes confunde a designação das localidades. A figura 2 apresenta o desenho da disposição das vilas e ramais de acesso no Maruanum.

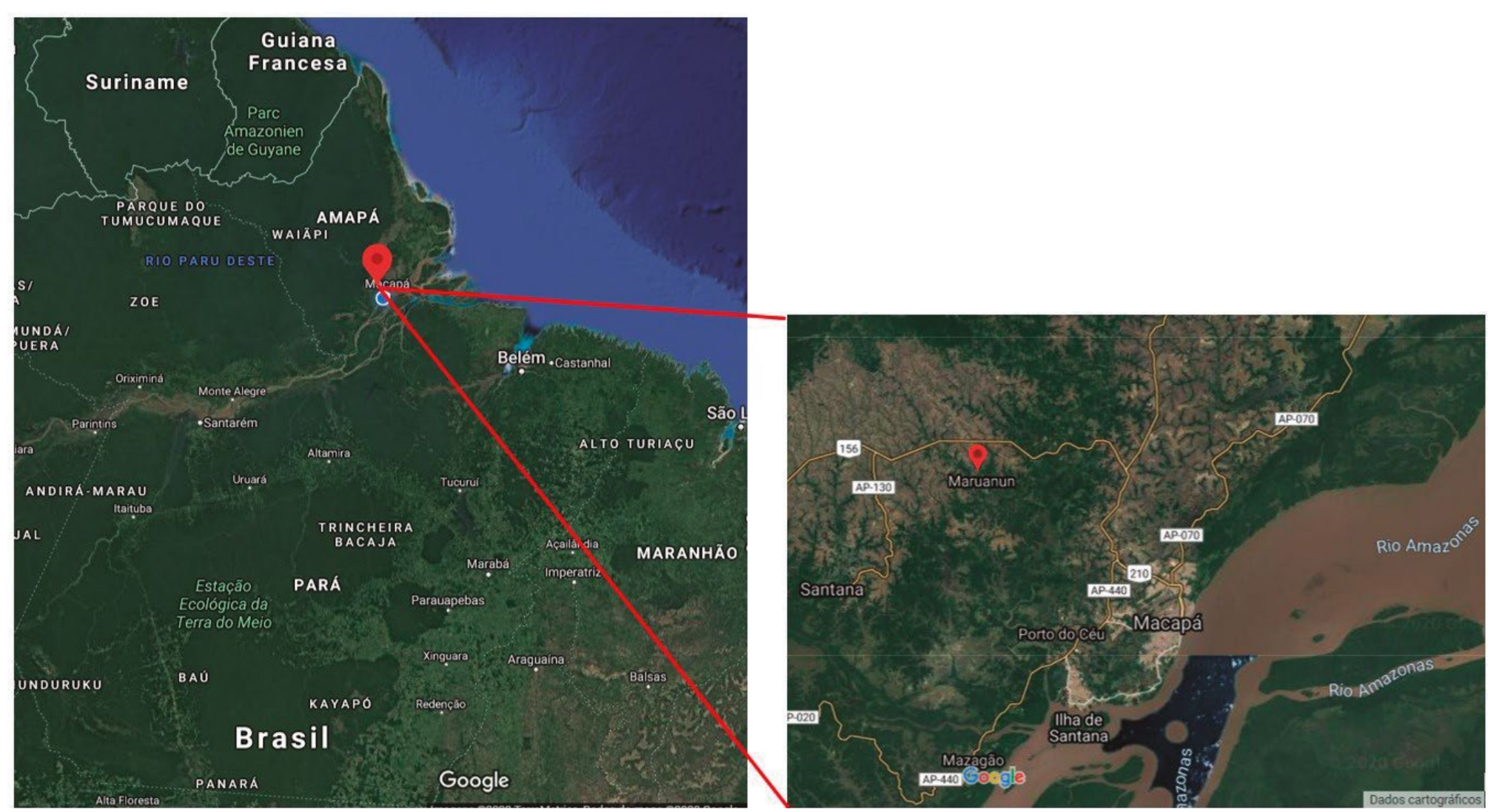

Figura 1 - Vista de satélite da região onde está a comunidade do Maruanum. Fonte: Google Maps 2020. 


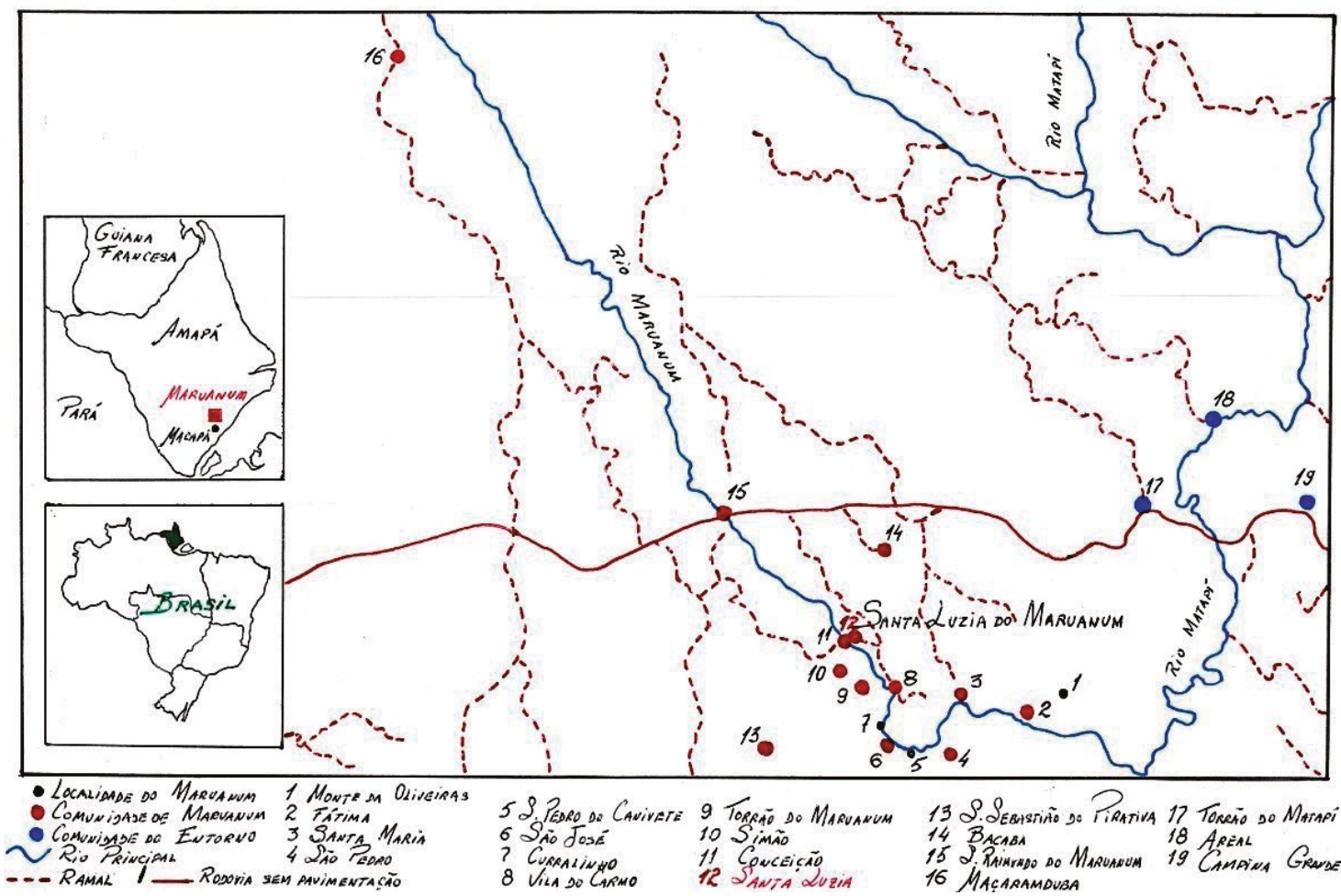

Figura 2 - Desenho da disposição das vilas e ramais de acesso no Maruanum. Elaboração própria (2019) com base em Henriques (2011).

“- Não é a louça do Maruanum, é o barro do Maruanum!"

(Trecho retirado do diário de campo da autora 2019)

Essa fala de dona Marciana sinaliza o seu lugar de referência, o rio Maruanum. Decerto que por onde corre o rio, correm também os elementos subjetivos do povo maruanense, como sua trajetória histórica e tradição. O rio Maruanum é uma importante fonte de recursos e via de transporte para a população local que ao longo do tempo passou a nutrir uma relação de dependência e respeito aos ciclos naturais, adotando sofisticados conhecimentos de uso e manejo deles (Silvani 2012), assim, suas crenças, valores, sistemas de conhecimento e práticas manifestam a mútua relação entre os grupos humanos e o ambiente, na qual ambos expressam as interações e os meios pelos quais elas se formaram (Maffi \& Woodley 2010).

As casas dos moradores, às margens do rio, são elementos que geograficamente possibilitam a identificação dos habitantes com o território, entendido como um processo de construção social resultante de uma ação coletiva que, de 
forma concreta e abstrata, se apropria (física e simbolicamente) de um espaço (Flores 2006). Na perspectiva poética de Loureiro (2016: 130), “[...] o rio e a floresta são como origens, um ponto zero, o lugar de todos os começos". Concordo com a definição de Almeida e Castrillón (2021), na qual o território está mais para verbo (movimento, ação de fazer e dinâmicas) do que para substantivo, assim, não existe identidade sem território.

O ritmo de vida na comunidade do Maruanum descrito por Coirolo (1991) é característico da região amazônica, o qual oscila entre o inverno (período de chuvas torrenciais, de dezembro a maio) e o verão (junho a novembro) - o peixe é abundante, as clareiras para a agricultura são abertas na floresta, as frutas amadurecem e as atividades das ceramistas do Maruanum se intensificam. Identifica-se ainda que boa parte das atividades praticadas na comunidade, mencionadas por Coirolo (1991), mescla o trabalho de homens e mulheres. As casas de farinha ${ }^{9}$ ainda são comuns no quintal das casas, geralmente estão erguidas sobre o chão de terra batida, como prática semelhante a dos povos indígenas, pois utilizam ainda as prensas de palha trançada (tipiti) e peneiras.
Nos últimos anos, com o aumento da interação da comunidade, homens e mulheres passaram a estudar e trabalhar em outras localidades, principalmente na cidade de Macapá, mas boa parte dos moradores, especialmente os mais velhos, ainda mantém ofícios relacionados à agricultura familiar e a extrativismo na região do Maruanum. Em adição, algumas vilas são atendidas por serviços básicos de infraestrutura, como a rede pública de iluminação, água tratada e serviço de telefonia. O ensino médio modular também foi incorporado à comunidade, embora receba fortes críticas pelo modo como foi estruturado.

\section{AS LOUCEIRAS DO MARUANUM: "DESDE QUE ME ENTENDI”}

As mulheres ceramistas do Maruanum se autodenominam "loiceiras", chamando os objetos que confeccionam de "loiças de barro" ou "loiças do Maruanum”, o que pode justificar seu autorreconhecimento (Ferreira 2016), constituindo símbolos que dão sentido e norteiam seus modos de estar no mundo (Matos 2011). A representatividade do "feminino" 10 opera na reprodução dessa prática cultural, podendo ser explicada por meio do olhar histórico-mitológico da cerâmica como uma das

9 Locais comuns nas comunidades rurais, onde são preparados os derivados da mandioca bastante apreciados na região amazônica, como a farinha d'água, a goma de tapioca (beiju) e o tucupi.

10 Relativo aos simbolismos de gênero. 
grandes artes da civilização (Lévi-Strauss 1985). Esse olhar, situado no contexto da trajetória histórica de sociedades ameríndias, desvela a confecção da cerâmica como uma atividade realizada especialmente por mulheres, de caráter sagrado e envolvendo uma série de particularidades como cuidados, proibições e mitos de origem e reprodução. Assim, apenas em algumas sociedades a cerâmica era feita por homens (Lévi-Strauss 1985).

Historicamente, a prática de conhecimento das louceiras do Maruanum é passada de geração em geração por meio da oralidade. Na cultura amazônica, os herdeiros de um modo de vida pautado na tradição oral expõem concepções de equilíbrio e respeito com o ambiente, assim como os ensinamentos deixados pelas primeiras comunidades que ocuparam a Amazônia (Pacheco 2012). Ao ser questionada se as louças sempre fizeram parte de seu cotidiano, dona Marciana traz recordações desde muito cedo, usando uma expressão recorrente: "desde que me entendi”, para se referir as suas memórias ${ }^{11}$. Segundo Mendes (2009), as sociedades têm diferentes formas de lidar com a temporalidade, nesse caso, existe o tempo mítico que se refere a um passado distante, e esse tempo, na maioria das vezes, situa-se nas origens da vida social. Destaca-se o diálogo a seguir:

\begin{abstract}
Dona Marciana: "Desde que me entendi as minhas tia já faziam artesanato, só que não tinha valor, era só ficar nas comunidade e encomenda mesmo de lá que faziam, depois deu grande me casar aí foi o pessoal aqui de Macapá, fizeram uma reunião com a gente pra formar a associação das loicera pra ter valor nas peça de artesanato."

Autora da pesquisa: "A senhora sabe de onde vem esse "saber fazer" da louça? Existe alguma história a respeito disso?"

Dona Marciana: "Bem, quando eu me entendi o que a minha avó dizia que foi dos índios, quando o pessoal ia roçar roça no mato, achava... Achava o pote, alguidar tudo no mato que quebraro, uns tava só a boca, outros quebrado, então entrevalo [sic], o pessoal foram pegando os caco das loiça mostrando pro pessoal daí a geração foi crescendo, tirando a argila pra fazer as peça de artesanato. entrevalo [sic], o pessoal foram pegando os caco das loiça mostrando pro pessoal daí a geração foi crescendo, tirando a argila pra fazer as peça de artesanato."
\end{abstract}

Nesse contexto, Ferreira (2016:174) observa em seu estudo que a cerâmica possui uma relação temporal antiga, seja com os indígenas ou com os negros, pois quando nas narrativas surgem menções aos "antigos" ou "mais velhos" é possível que haja divergências de opiniões, nesse caso, as louceiras rememoram o conhecimento de tecer a cerâmica até uma determinada geração de mulheres, antes disso, elas contam as histórias sobre os antepassados presentes na memória coletiva. Essa distinção é interpretada por Jacques (2015: 61), em seu estudo na comunidade quilombola de Cinco

11 Segundo Bosi (2003), a memória é reconstituída pelo presente, sendo marcada por experiências vividas e transformadas ao longo do tempo. 
Chagas, próxima à comunidade do Maruanum, quando traz diferenciações entre as interpretações relacionadas aos cacos - "vestígios de alguém que habitou a comunidade e que ninguém conheceu [...]" - e à igaçaba ${ }^{12}$ - "algo feito por alguém, 'os antigos', aqueles que estão presentes na história contada pelos mais velhos [...]”.

As experiências descritas por Jacques (2015) apresentam um conjunto de relações das suas trajetórias histórico-culturais com a comunidade do Maruanum, especialmente, em vestígios arqueológicos que ajudam a desvelar marcas temporais e multiétnicas dos objetos. A autora narra que os inúmeros fragmentos e vasilhames cerâmicos espalhados pela área de Cinco Chagas apresentam características semelhantes às descritas por dois estudos de Meggers e Evans $(1950,1957)$ sobre os vestígios enquadrados na fase Mazagão e que podem, portanto, estar associados a uma ocupação indígena pré-colonial e do momento de contato. No entanto, a autora observa que outros fragmentos cerâmicos encontrados apresentam características que se assemelham às louças antigas feitas pelas louceiras do Maruanum. Sobre isso, os membros da comunidade relatam que vasilhas para colocar água, torrar café e cozinhar eram frequentemente encomendados do Maruanum em um dado período no tempo (Jacques 2015).

\section{AS LOUÇAS DE BARRO: "TEM TODA UMA CIÊNCIA"}

O processo de confecção das louças ocorre duas vezes ao ano influenciado pela dinâmica hidrológica do estuário amazônico: no verão, quando a maré baixa, as louceiras saem em mutirão pelo rio Maruanum evocando cânticos tradicionais nas canoas até a chegada ao "barreiro", às margens do rio. Ao escolherem o local exato de extração, elas pedem licença à "mãe do barro" ou "vozinha" para a retirada da argila. Aproximando esse elemento da encantaria amazônica ao ensaio "arte ciumenta" de Lévi-Strauss (1985: 40), se encontra uma personagem sob diversas designações, tais como a "Mãe Terra", "Avó da Argila" e "Senhora da Argila", considerada uma benfeitora, uma vez que "a humanidade lhe devia matéria-prima, técnicas e a própria arte", mas paralelamente revelava "uma faceta temperamental, ciumenta e rabugenta".

O mesmo autor identificou o mito de uma divindade do barro nas crenças de muitos povos ameríndios, dentre eles, os Tacana, da Bolívia, os quais contam que a "[...] avó da argila ensinou as mulheres a modelar vasos de terra, cozê-las e torná-las resistentes" (Lévi-Strauss 1985: 39). No Sudeste da Colômbia, os Tanimuka ou Ofaina acreditam que "[...] a mulher primordial, instituiu a arte da cerâmica. Ela é a senhora dos potes, que

12 Termo empregado para se referir às vasilhas inteiras encontradas na roça de mandioca (Jacques 2015). 
não podem ser fabricados sem a sua permissão" (Lévi-Strauss 1985: 39), também existem relatos de oferendas a essas divindades, nos quais as mulheres que buscam a argila pela primeira vez, deixam "um vaso e um punhado de coca como oferenda à 'Namatu', para obter sua autorização” (LéviStrauss 1985: 40).

Sobre as narrativas míticas, Sapiezinskas (2012) conclui que elas são significativas para um grupo porque geralmente estão ligadas à origem do mundo e à sua forma de enxergá-lo, podendo ser entendidas como cosmovisões que se referem a um conjunto de crenças que operam no ordenamento do mundo social. No que tange à narrativa mítica amazônida, Paes Loureiro $(2008,2016)$ ressalta que predomina uma poética do imaginário, na qual divindades como a "mãe do barro" compõem a etnodramaturgia imaginária de encantarias ao transfigurar o real pela impregnação do imaginário poético.

Ao refletir sobre as encantarias afro-indígenas na Amazônia marajoara, Pacheco (2010) usa a historiografia para discutir as punições eclesiásticas sobre a religiosidade das populações amazônicas desde o período colonial, em que a resistência de suas crenças era sustentada pelo imaginário religioso que comportava seus valores culturais e tradições. Ao longo do tempo, a "voz nativa" da Amazônia (Maués 1999) foi sobrevivendo e respeitando o caráter individual e sincrético da cultura indígena associada aos cultos trazidos com as diásporas africanas (Pacheco 2010).

Nesse contexto, os africanos destituídos de seus direitos, recriaram no rastro de suas memórias uma nova cultura material e imaterial presente em suas linguagens históricas e artísticas que interagiam com os modos de vida dos indígenas, essas identificações permitiram a trajetória de vida desses grupos na Amazônia e a construção de um sistema de pertencimento em que as suas expressões étnico-raciais comportavam as referências dos grupos nativos dessa região (Pacheco 2011). Ainda para o autor, os indígenas, negros e seus descendentes conformaram memórias, saberes e modos de ser afro-indígenas, o que demonstra a força das heranças de "continuidades históricas"13 no presente.

Em relação à "mãe do barro", dona Marciana relata:

“[...] quando a gente chega pra tirar o barro, a gente tem que tirar, tirar licença da mãe do barro...tem que tirar licença da mãe do barro pela...deixar a gente tirar nosso barro e fazer nossas peça pra queimare em paz...então quando nós telmina de tirar o barro, cada uma loicera, faz uma pecinha e oferece de "ofelta" pra mãe do barro,

13 Pacheco (2011: 45) explica o uso de "continuidades históricas" em contraposição às "permanências históricas", para se referir a um caráter dinâmico. Nos aspectos discursivos, elas permitem "recriações, revisões, invenções, pois contextualiza sujeitos, motivações e perspectivas de mundo”. 
coloca lá tudo dentro do buraco, depois que a gente tapa o buraco que tiremo o barro."

Até um dado período, a etapa de retirada do barro era realizada exclusivamente pelas mulheres, pois a presença dos homens não era permitida, pois se acreditava que a "mãe do barro" faria a "veia do barro” desaparecer (Silvani 2012: 41). No entanto, há um grande esforço a ser empreendido nesta etapa fazendo com que a participação dos homens seja recorrente. Ainda existe uma crença de que o barro utilizado na fabricação da louça não pode entrar em contato com instrumentos metálicos, pois a deixaria impura fazendo com que se quebrasse durante a queima, por isso, são utilizadas toras de madeira e as próprias mãos para a abertura dos buracos. Para a realização dessas tarefas, as mulheres obedecem a algumas regras: devem observar a fase da lua tanto na extração da argila quanto do caripé ${ }^{14}$; as mulheres que participarão do mutirão não devem estar menstruadas, pois isso implicaria na "contaminação" da argila, as mulheres grávidas também são impedidas de participar, pois poderiam "empanemar" ${ }^{15}$ a argila e a casca do caripé (Coirolo 1991: 78).
Quando concluída a extração, cada ceramista modela uma louça pequena como oferta à "mãe do barro" e a coloca no buraco de onde houve a extração. Em seguida, o buraco é fechado para evitar acidentes como afogamentos de pessoas e do gado. Ao final, as louceiras carregam o barro sobre as suas cabeças até as canoas e retornam às suas casas. O estudo de Coirolo (1991) descrevia ainda o uso das folhas de bananeira e sororoca para embrulhar as bolas de barro que eram presas com a própria nervura, no entanto, estudos mais recentes, como os de Ferreira (2016) e Silva (2019), já descrevem o uso de sacolas plásticas para acondicionar o barro após a extração. A figura 3 mostra uma compilação de registros dos processos descritos acima.

A segunda etapa consiste na preparação e modelagem do barro, para isso, as louceiras preparam a argila retirando resíduos de raízes e rochas. O processo é seguido pela queima e peneira das cinzas do caripé, que são misturadas ao barro servindo como antiplástico. A partir daí, as louceiras amassam e batem o barro para extrair todo o ar, adicionando água para formar uma pasta homogênea e acinzentada (Silvani 2012). A figura 4 mostra parte da modelagem da massa.

14 Pronúncia popular do cariapé, designação das árvores do gênero Licania scabra (Ferreira 2016).

15 No sentido de má-sorte, agouro (Coirolo 1991). 


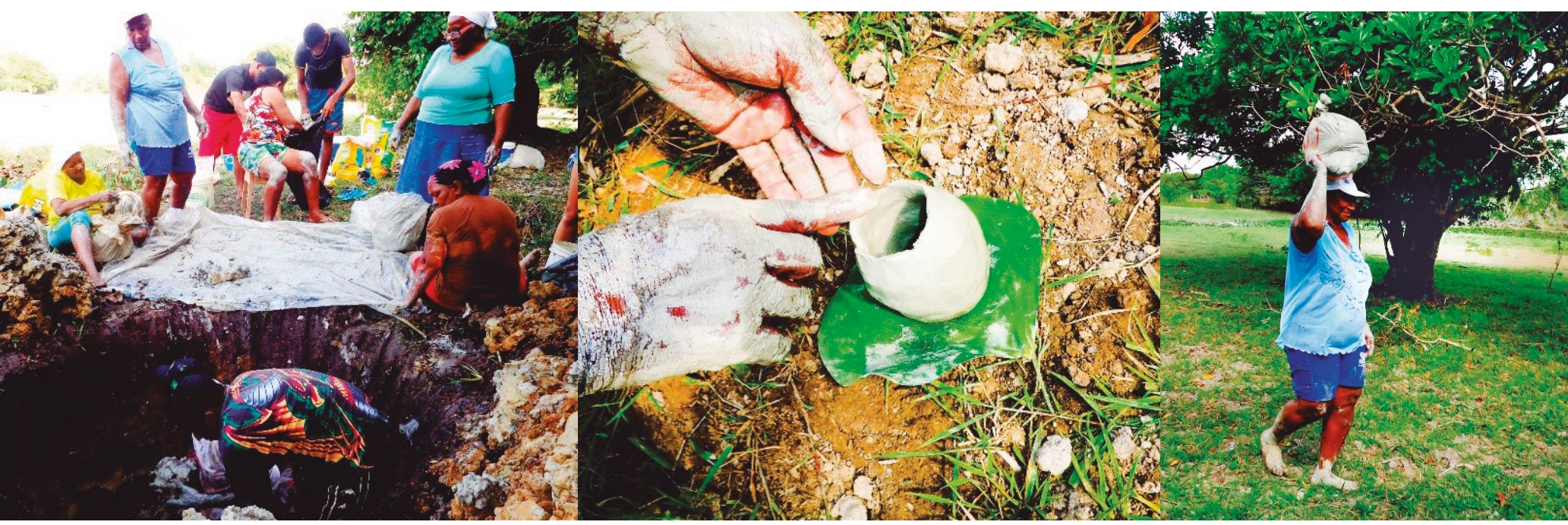

Figura 3 - Compilação de registros dos momentos de extração da argila: a louça sendo modelada como oferta à "mãe do barro", uma louceira carregando a matéria-prima até a canoa (da esquerda à direita). Fotos: Ernandes Melo para o Museu de Arqueologia e Etnologia do Amapá (2017).
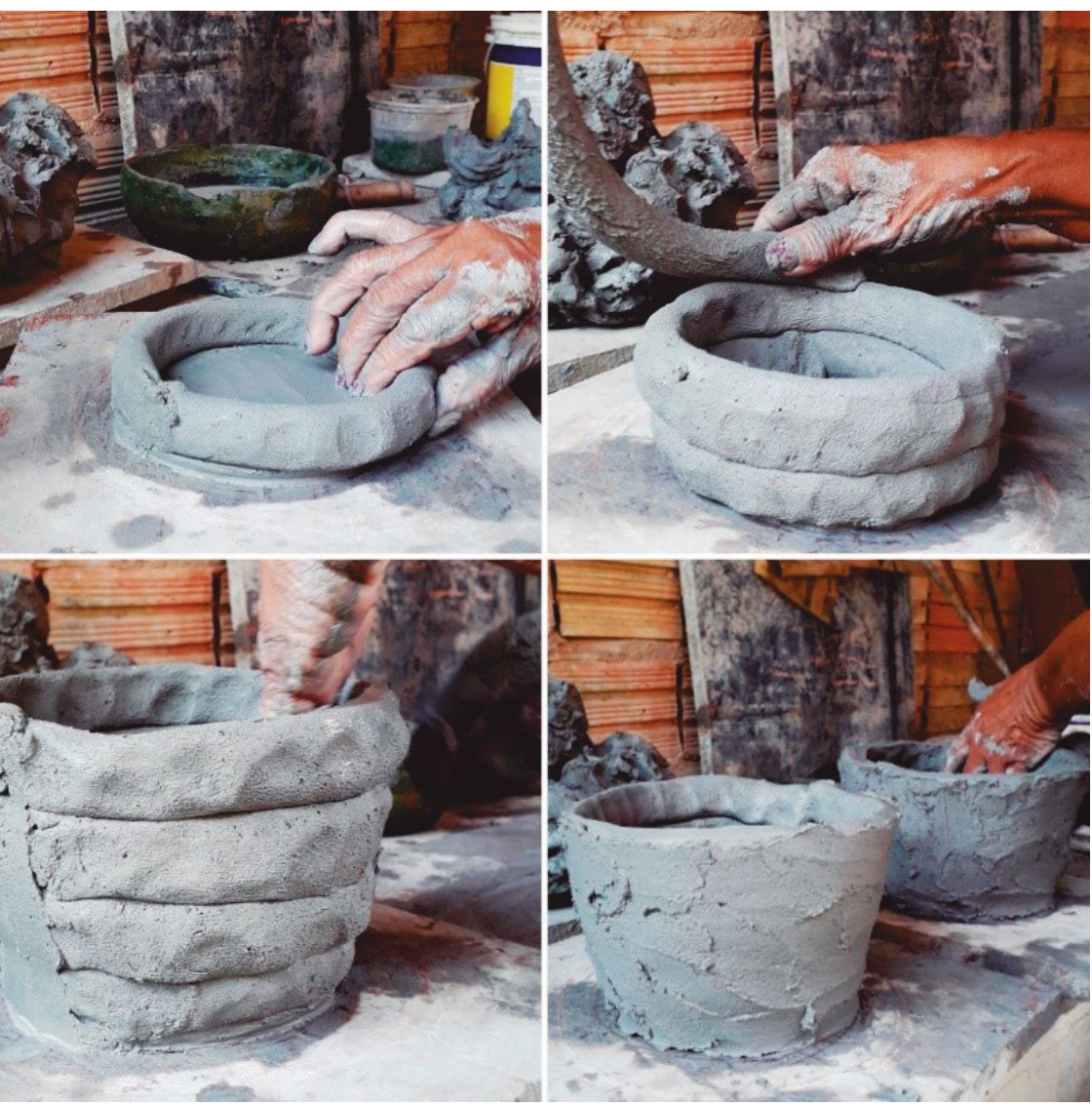

Figura 4 - Compilação do processo de modelagem de uma louça.

Fotos: da autora (2019). 
As mulheres trabalham individualmente sobre uma tábua ou bancada no quintal ou na cozinha de suas casas. Elas modelam as peças com marcas próprias que vão desde linhas e traços, até a composição de formas geométricas e símbolos das paisagens feitos com ferramentas utilizadas durante a modelagem da peça, como o cuiepel $^{16} \mathrm{e}$ oreipe $^{17}$. Os padrões de desenhos geralmente estão ligados à origem da comunidade e aos imaginários - um modo cultural de participação na construção da realidade social, expressando a imaginação simbólica de/e ou sobre uma época ou lugar (Rocha 2016) - ou ainda são marcas herdadas de gerações femininas anteriores, a identidade ancestral. Ao expandir subjetividades, os desenhos designam o lugar de memória, o que significa o espaço comum no qual a tradição é recriada por meio de um processo de identificação coletiva (Motta 1992), incidindo sobre um conjunto de representações partilhadas (Candau 2014) circunscrito pela realidade compartilhada que nutre discursos ao conectar o presente com o passado, bem como as imagens que dela são construídas (Hall 2014).

$\mathrm{Na}$ etapa seguinte, as louças são expostas ao sol, ao longo de um dia (no verão) ou até 15 dias (no inverno), para que atinjam o ponto de secagem ideal para o "burnimento", que é o processo de polir a peça até que adquira brilho e o acabamento necessários para a sua queima (Ferreira 2016), esse processo é feito com um tipo de seixo ${ }^{18}$. A seguir, são feitas fogueiras ao ar livre, geralmente no quintal da casa da louceira, onde as peças são colocadas para a primeira fase de seu "esquentamento", essa queima é feita individualmente ou em grupos, dependendo dos tamanhos das peças, que são viradas sobre rochas ou tijolos e envolvidas por pedaços de madeira seca em chamas.

Ao final da queima, as peças são retiradas da fogueira e procede-se a impermeabilização, para o qual uma vara com a resina de jutaicica ${ }^{19}$, amarrada em sua ponta, é roçada na louça para revesti-la com um brilho marrom. As louceiras do Maruanum modelam panelas, fogão (ou fogareiro), alguidares, churrasqueiras, caramuché, candeeiro, tigelas e diversas outras peças tradicionalmente utilizadas pela comunidade e que ao longo do tempo passaram a ser vendidas fora dela. Dentre os objetos mencionados, encontram-se as louças compiladas na figura 5, adquiridas durante a pesquisa de campo.

16 Lagenaria vulgaris, nome científico de um tipo de cabaça (Ferreira 2016).

17 Pycnoporus sanguineus, nome científico do fungo de madeira conhecido como "orelha de pau" (Ferreira 2016).

18 Junto aos pilões que moem o cariapé, os seixos são guardados por gerações e utilizados enquanto são duráveis (Ferreira 2016).

19 Hymenaea courbaril, nome científico do jatobá, jatobazeiro ou jutaiceiro (Coirolo 1991, Ferreira 2016). 

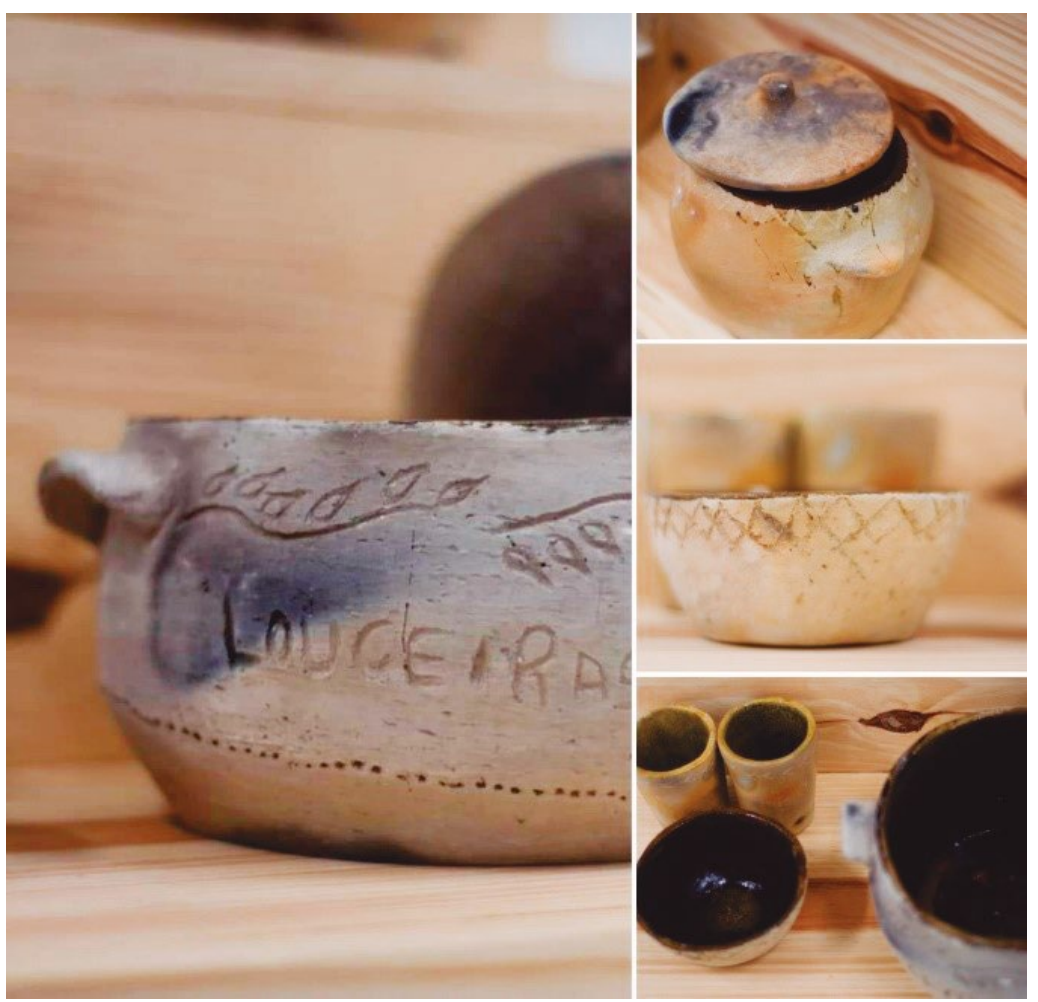

Figura 5 - Compilação de registro das louças do Maruanum. Fotos: Bruno de Oliveira da Silva (2019).

Em seu estudo, Coirolo (1991: 91) destaca que as crenças na "panema" ou "mau-olhado" são elementos assimilados de práticas indígenas e que a fabricação da cerâmica "é a mesma utilizada pelos grupos indígenas de toda Bacia Amazônica [..]. A modelagem por roletado e uso da cinza de cariapé como antiplástico, são uma comprovação disso". O pesquisador e professor Edinaldo Nunes Filho $(2019)^{20}$ relata que as louças do Maruanum

representam a combinação da cultura material africana e ameríndia que existiram na atual região do Igarapé do Lago. Sendo que os artefatos cerâmicos produzidos possuem técnicas, morfologia e estilos característicos de antigos grupos humanos que habitaram/residiram na região em tela. (Filho 2019: s.p.).

Para Costa, Lima e Custódio (2016: 209), as louceiras do Maruanum transportam uma "culminância cultural indígena e africana" por meio da memória, tradição oral e identidade cultural, inaugurando um "criar-saber-fazer" como um conjunto representacional a partir dela mesma e de suas relações sociais e culturais que agregam o seu significado.

20 Em conversa para a construção desta pesquisa. 


\section{CONCLUSÕES}

Diante do exposto, alguns pontos pertinentes devem ser ressaltados, o primeiro deles diz respeito à extração do barro coordenado por uma série de rituais que implica no uso racional dos recursos naturais. Com essa dinâmica, é assegurada o que Costa (2011) infere como consciência ecológica baseada na concepção de "prevenção" de Milaré (2005) e "precaução" de Fiorillo (2011), que atestam o conhecimento das louceiras do Maruanum como um instrumento de proteção do território onde reproduzem suas práticas culturais. Outro ponto destacado é que os valores alcançados com a comercialização das peças é parte importante na renda doméstica (Santos 2016).

Cabe mencionar que os visitantes da comunidade até meados de 2019, antes das condições impostas pela pandemia da SARS-CoV-2 (Covid-19), eram recebidos constantemente na casa das mulheres ceramistas e demonstravam interesse em participar do ritual que envolve a confecção das louças como uma forma de aproximação com a cultura local, assim, foi identificado o espaço para que se estabelecesse uma relação de dádiva $^{21}$ e hospitalidade (Silva \& Rossini 2019). No entanto, o atual cenário de crises globais renovadas e intensificadas pela crise sanitária suscita novos protocolos de pesquisas voltadas a (re)construir essas e outras formas de interação com as comunidades tradicionais. Sendo necessário, portanto, unir a ciência às narrativas representantes de lutas socioambientais centradas na defesa da terra e dos territórios (Martinelli 2020).

Nesse sentido, o trabalho interdisciplinar é uma prática para se criar marcos epistemológicos para a interpretação da realidade, reconhecendo ainda que o conhecimento deverá ser construído junto aos "profundos conhecedores dos 'segredos' da floresta" (Aragón 2015:10). Um último ponto a ser destacado é a criação do Centro de Exposição das louceiras do Maruanum, em dezembro de 2020, que viabilizou um novo espaço para a comercialização das louças de barro, além de ofertar oficinas e atividades centradas na educação patrimonial (Figura 6).

Existe uma notória visualização social da atividade das mulheres ceramistas, tanto por parte do Estado e de organizações não governamentais quanto por parte da sociedade amapaense, contudo, existem fragilidades e desafios em relação às políticas de fomento (Santos 2016). O Centro de Exposição pode impulsionar, portanto, novas estratégias de promoção do desenvolvimento local, construído do interno para o externo, onde o local é um desafio iminente para desenvolver ações que promovam a inclusão produtiva e social. Assim, as referidas ações dependem da capacidade dos 
são refletidos pelos - sentidos e modos de estar no mundo das mulheres ceramistas. Nesse ínterim surgem questões centrais suscitadas no contato com a realidade social, na qual dona Marciana trata da luta pelas políticas socioambientais de seu território, busca da valorização de sua arte e demonstra a indignação pela exploração predatória do cariapé e da jutaicica, matérias-primas que constituem a identidade das louças. Tais questões se tornam inerentes na fundamentação dos caminhos que vislumbro percorrer.

Nesse entendimento, é necessária a busca pela aproximação dos conhecedores tradicionais e cientistas a fim de serem discutidas as diferentes formas de produção de conhecimento (do que é produzido nas comunidades tradicionais e nos centros de pesquisa e laboratórios) (Silva 2019). Para tanto, a proposta do relato etnográfico é inspirada em analíticas seminais das literaturas pósetnográficas que rompem com o sentido clássico da etnografia e entremeiam o ressurgimento de dois mundos, corpos e cosmos (Oliveira 2020). A exemplo, o "pacto etnográfico" mencionado por Castro (2015:12) como um aprendizado no livro "A queda do céu", que evidencia como novas formas de ler ajudam a compor um repertório de técnicas (Oliveira 2020). Assim, este texto introduz uma experiência de compartilhamento em andamento que buscará novas maneiras de olhar sujeitos e objetos. Na dada realidade social, as questões centrais voltam-se para a importância da valorização do conhecimento tradicional das mulheres ceramistas e a preservação e conservação da arte do quilombo, que fornece elementos inspiradores para a criatividade humana, relações sociais e harmonia com a natureza.

\section{REFERÊNCIAS}

Almeida, Flávia Leme. 2010. Mulheres recipientes: recortes poéticos do universo feminino nas artes Visuais. São Paulo: Editora Unesp.

Almeida, Alfredo Wagner Berno e Castrillón, Antonio. 2021. Elementos para reflexões sobre a Nova Cartografia Social. Seminário da Nova Cartografia Social da Amazônia - Universidade de Magdalena (Online), in disciplina de Fundamentos Epistemológicos da Interdisciplinaridade. Programa de PósGraduação em Desenvolvimento Sustentável do Trópico Úmido. Núcleo de Altos Estudos Amazônicos, Universidade Federal do Pará, Belém. 
Almeida, Inailde e Almeida, Oriana Trindade de. 2016. O capital social e o desenvolvimento local: estudo de caso das cooperativas agrícolas no município de Santarém, Pará. Papers do NAEA. 356: 3-19. http://www.naea.ufpa.br/naea/novosite/index.php?action=Publicacao.arquivo\&id=636

Aragón, Luis E. 2015. Desenvolvimento amazônico em questão. Revista Crítica de Ciências Sociais. 107:5-16. http://www.scielo.mec.pt/pdf/rccs/n107/n107a02.pdf

Candau, Jöel. 2014. Memória e identidade. São Paulo: Contexto.

Castro, Eduardo Viveiros de. 2015. Prefácio, in A queda do céu: palavras de um xamã yanomami, pp. 11-41. São Paulo: Companhia das Letras.

Cavalcanti, Alberes de Siqueira. 2014. Olhares epistemológicos e a pesquisa educacional na formação de professores de ciências. Educação e Pesquisa: Revista da Faculdade de Educação da Universidade de São Paulo. 40(4): 983-998. https://doi.org/10.1590/s1517-97022014121459

Coirolo, Alicia. 1991. Atividades e tradições dos grupos ceramistas do Maruanum (AP). Boletim Museu Paraense Emilio Goeldi, Série Antropologia. 7(1):71-94.

Costa, Célia Souza da. 2011. Louceiras do Maruanum em observância aos princípios ambientais: prevenção, precaução e função socioambiental da propriedade. Planeta Amazônia: Revista Internacional de Direito Ambiental e Políticas Públicas. 3: 145-152. https://periodicos.unifap.br/index.php/planeta/ article/view/554/CostaN3.pdf

Costa, Célia Souza da; Lima, Wanda Maria da Silva Ferreira e Custódio, Elivaldo Serrão. 2016. A arte cerâmica do Maruanum: A encantaria como linguagem artística. Identidade! 21 (2): 199-212. http:// periodicos.est.edu.br/index.php/identidade/article/view/2935

Costa, Célia Souza da e Custódio, Elivaldo Serrão. 2017. Religião, cultura e políticas públicas no Amapá: religiosidade, cerâmica e encantaria na tradição das Louceiras do Maruanum. Revista Eletrônica Correlatio. 16 (2): 209-227. http://dx.doi.org/10.15603/1677-2644/correlatio.v16n2p209-227

Ferreira, Fabrício Costa. 2016. "Desde que me entendi": tecendo saberes e fazeres relativos à louça da comunidade quilombola do Maruanum. Dissertação de mestrado, Universidade Federal do Pará, Belém.

Fiorillo, Celso Antonio Pacheco. 2011. Curso de Direito Ambiental Brasileiro. São Paulo: Saraiva. 
Flores, Murilo. 2006. A identidade cultural do território como base de estratégias de desenvolvimento: uma visão do estado da arte (Projeto RIMISP). Territorios con identidad cultural. https://static.fecam. net.br/uploads/28/arquivos/4069_FLORES_M_Identidade_Territorial_como_Base_as_Estrategias_ Desenvolvimento.pdf

Flick, Uwe. 2004. Uma introdução à pesquisa qualitativa. Porto Alegre: Bookman.

Gomes, Flávio. 1999. Nas terras do Cabo Norte: fronteiras, colonização e escravidão na Amazônia brasileira (séculos XVII-XIX). Belém: UFPA.

Hall, Stuart. 2014. A identidade cultural na pós-modernidade. Rio de Janeiro: Lamparina.

Iphan. 2014. Marabaixo. http://portal.iphan.gov.br/pagina/detalhes/1941

Krenak, Ailton. 2019. Ideias para adiar o fim do mundo. São Paulo: Companhia das Letras.

Lagrou, Els e van Velthem, Lucia Hussak. 2018. As artes indígenas: olhares cruzados. Revista Brasileira de Informação Bibliográfica em Ciências Sociais. 87: 133-156. https://www.anpocs.com/index.php/bibpt/bib-87/11596-as-artes-indigenas-olhares-cruzados/file

Lévi-Strauss, Claude. 1985. A oleira ciumenta. São Paulo: Editora Brasiliense.

Paes Loureiro, João de Jesus. 2008. A arte como encantaria da linguagem. São Paulo: Escrituras Editora. Paes Loureiro, João de Jesus. 2016. Meditação devaneante entre o rio e a floresta. Arterias. 3:126-132. http://dx.doi.org/10.18542/arteriais.v3i3.3924

Paes Loureiro, João de Jesus. 2018. Cultura Amazônica: uma poética do imaginário. Belém: Cultura Brasil.

Maffi, Luisa e Woodley, Ellen. 2010. Biocultural Diversity Conservation: a global source book. London: Earthscan.

Martinelli, Bruno Marangoni. 2020. O INPA e os povos e comunidades tradicionais: aproximações sobre o saber científico e reflexões sobre uma virada ontoepistemológica. Tese de doutorado, Universidade de Brasília, Brasília.

Matos, Sônia Missagia. 2001. Artefatos de gênero na arte do barro: masculinidades e femininidades. Estudos Feministas. 9 (1): 56-80. https://doi.org/10.1590/S0104-026X2001000100004 
Maués, Raimundo Heraldo. 1999. Uma outra invenção da Amazônia: religião, histórias, identidades. Belém: CEJUP.

Mendes, Francisca Raimunda Nogueira. 2009. A louça de barro do Córrego de Areia: tradição, saberes e itinerários. Tese de doutorado, Universidade Federal do Ceará, Fortaleza.

Milaré, Édis. 2005. Direito do ambiente: A gestão ambiental em foco. São Paulo: RT.

Motta, Marly Silva da. 1992. A nação faz cem anos: a questão nacional no cenário da Independência. Rio de Janeiro: Editora da FGV-CPDOC.

Oliveira, Eduardo Jorge. Literaturas pós-etnográficas: uma leitura de A queda do céu. Brésil(s). Sciences humaines et sociales. 3. https://doi.org/10.4000/bresils. 8842 .

Pacheco, Agenor Sarraf. 2010. Encantarias Afro-indígenas na Amazônia Marajoara: Narrativas, Práticas de Cura e (In)tolerâncias Religiosas. Horizonte: revista de estudos de Teologia e Ciências da Religião. 8 (17): 88-108. https://doi.org/10.5752/P.2175-5841.2010v8n17p88

Pacheco, Agenor Sarraf. 2011. Astúcias da Memória: identidades afroindígenas no corredor da Amazônia. Revista Tucunduba. 2: 40-51. http://www.revistaeletronica.ufpa.br/index.php/tucunduba/ article/viewArticle/46

Pacheco, Agenor Sarraf. 2012. Cosmologias afroindígenas na Amazônia Marajoara. Projeto História. 44: 197-226. https://revistas.pucsp.br/revph/article/view/10219/9821

Rocha, Gilmar. 2016. A imaginação e a cultura. Teoria e Cultura. 11(2): 167-187. https://periodicos.ufff. br/index.php/TeoriaeCultura/article/view/12277.

Santos, Kátia Paulino dos. 2016. Associação de Mulheres Louceiras do Maruanum (ALOMA): tradição e economia solidária no Estado do Amapá-Amazônia-Brasil. Revista Gestão em Análise. 5 (2): 47-63. http://dx.doi.org/10.12662/2359-618xregea.v5i2.p47-63.2016

Sapiezinskas, Aline. 2012. Como se constrói um artesão: negociações de significado e uma 'cara nova' para as 'coisas da vovó, in Horizontes Antropológicos: saberes e fazeres, pp. 133-158. Porto Alegre: UFRGS.

Silvani, Juliana Morilhas. 2012. O valor da cultura: Um estudo de caso sobre a inserção da Louça do Maruanum/AP no mercado e sua relação com a preservação do patrimônio cultural. Dissertação de mestrado, Instituto do Patrimônio Histórico e Artístico Nacional, Rio de Janeiro. 
Superti, Eliane e Silva, Gutemberg de Vilhena. 2015. Comunidades quilombolas na Amazônia: construção histórico-geográfica, características socioeconômicas e patrimônio cultural no Estado do Amapá. Confins: Revista Franco-Brasileira de Geografia. 23. https://doi.org/10.4000/confins.10021

Silva, Elloane Carinie Gomes. 2019. As louceiras do Maruanum e o turismo cultural na região amazônica. Dissertação de mestrado, Universidade do Vale do Itajaí, Balneário Camboriú.

Silva, Elloane Carinie Gomes e Rossini, Diva de Mello. 2020. Dádiva e hospitalidade: o encontro com as louceiras do Maruanum, no Amapá. Revista Hospitalidade. 17(1): 1-17. https://doi.org/10.21714/21799164.2020.v17n1.001

Stengers, Isabelle. 2002. A invenção das ciências modernas. São Paulo: Editora 34.

Toledo, Victor Manuel e Barrera-Bassols, Narciso. 2008. La Memoria biocutural: La importancia ecológica de las sabidurías tradicionales. Barcelona: Icaria. 